\title{
Resistance to the Emerging Moroccan Watermelon Mosaic Virus in Squash
}

\author{
Manuel Miras, ${ }^{1}$ Miguel Juárez, ${ }^{2}$ and Miguel A. Aranda ${ }^{1, \dagger}$ \\ ${ }^{1}$ Centro de Edafología y Biología Aplicada del Segura, Consejo Superior de Investigaciones Científicas, 30100 Espinardo, Murcia, Spain; \\ and ${ }^{2}$ Escuela Politécnica Superior de Orihuela, Universidad Miguel Hernández de Elche, 03312 Orihuela, Alicante, Spain \\ Accepted for publication 20 December 2018.
}

\begin{abstract}
Moroccan watermelon mosaic virus (MWMV) represents an emerging threat to cucurbit production in the Mediterranean Basin. We sequenced the near complete genome of MWMV-SQ10_1.1, a cloned Spanish isolate. MWMV-SQ10_1.1 has the typical potyvirus genomic structure, and phylogenetic analysis showed that it shared a common ancestor with other Mediterranean MWMV isolates. We used MWMV SQ10_1.1 to inoculate plants in a collection of commercial squash cultivars, including some described as potyvirus resistant. All inoculated plants from all cultivars showed severe infection symptoms. Twenty-four Cucurbita spp. accessions were then tested for their susceptibility to MWMV-SQ10_1.1. Plants of the C. ecuadorensis PI 432441 accession showed no symptoms and their enzyme-linked immunosorbent assay readings were similar to uninfected controls. Progeny analysis of F1 and F2 populations suggested that two
\end{abstract}

ABSTRACT

Squash (Cucurbita pepo L.) is an important vegetable crop worldwide (Food and Agriculture Organization of the United Nations 2016). Potyviruses, including zucchini yellow mosaic virus (ZYMV), papaya ringspot virus (PRSV), and watermelon mosaic virus (WMV), can cause significant economic losses in squash and other cucurbit crops (Juárez et al. 2013a; Lecoq 2003; Lecoq and Desbiez 2012). Moroccan watermelon mosaic virus (MWMV; genus Potyvirus, family Potyviridae) is another potyvirus first described infecting cucurbits in Morocco in 1974 (Fischer and Lockhart 1974; Lecoq 2003) and has since been reported in South, Central, and North Africa and in European Mediterranean countries (Arocha et al. 2008; Bananej et al. 2018; Chatzivassiliou et al. 2016; Ibaba et al. 2016; Lecoq et al. 2001, 2008; Malandraki et al. 2013; Menzel et al. 2011; Roggero et al. 1998; Yakoubi et al. 2008). Currently, MWMV is considered an emergent threat to cucurbit production at least in Mediterranean countries (Fischer and Lockhart 1974; Lecoq 2003).

Sources of resistance to potyviruses, such as MWMV, ZYMV, PRSV, and WMV, have been identified in cucurbit species (Brown et al. 2003; Grumet et al. 2000; Ling et al. 2009; Provvidenti 1991; Ullah and Grumet 2002; Wai and Grumet 1995). Specifically, resistance to MWMV has been found in Cucumis metuliferus, Citrullus ecirrhosus, and Cucumis sativus (Kabelka and Grumet 1997; Ling et al. 2009; Meer and Garnett 1987). In Cucumis sativus, progeny analysis of segregant families showed that resistance to MWMV is controlled by a single recessive gene. Interestingly, analysis of the resistance to ZYMV in the same $\mathrm{F} 3$ population indicated that resistance to both viruses is conferred

${ }^{\dagger}$ Corresponding author: M. A. Aranda; m.aranda@cebas.csic.es

Funding: This work was supported by the Región de Murcia, Consejería de Empleo Universidades y Empresa RIS3MUR program (grant 2I16SA000057) and the Ministerio de Economía, Industria y Competitividad within the ERA-Net 61827 ARIMNet 2 program (grant PCIN-2017-055).

*The $\boldsymbol{e}$-Xtra logo stands for "electronic extra" and indicates that three supplementary figures and one supplementary table are published online.

The author(s) declare no conflict of interest.

(C) 2019 The American Phytopathological Society recessive genes control PI 432441 resistance to MWMV. We hypothesized that this resistance could be associated with alleles of genes encoding the eukaryotic translation initiation factor 4E (eIF4E), particularly after determination of its recessive nature. A multiple sequence alignment including the two eIF4E ortholog sequences from PI 432441 (CeeIF4E1 and CeeIF4E2) identified three amino acid substitutions in CeeIF4E1 and two amino acid substitutions in CeeIF4E2 potentially involved in potyvirus resistance. Polymerase chain reaction markers for CeeIF4E1 and CeeIF4E2 were developed and used to genotype 156 F2 individuals already phenotyped; this analysis did not support an association of either CeeIF4E2 or CeeIF4E1 with MWMV resistance.

Keywords: cucumber, pumpkin. by the same recessive gene or by two linked genes (Kabelka and Grumet 1997). However, Cucumis sativus is not crossable with Cucurbita spp.; thus, sources of resistance to MWMV need to be identified within the genus Cucurbita. The genomes of three Cucurbita species have been determined; species in this genus appear to be allotetraploids resulting from a whole genome duplication that took place between 3 to 30 million years ago, with the two subgenomes having a similar number of genes and neither subgenome globally dominant in terms of gene expression (Montero-Pau et al. 2018; Sun et al. 2017).

For members of the family Potyviridae, resistance genes are often recessively inherited and have been shown in many instances to encode eukaryotic translation initiation factors (eIFs) of the 4E and 4G families, such as eIF4E, eIF(iso)4E, eIF4G, and eIF(iso)4G (Bastet et al. 2017; Gallois et al. 2018; Hashimoto et al. 2016; Sanfaçon 2015; Truniger and Aranda 2009). These natural resistance alleles have been identified in numerous crops, such as pepper, tomato, lettuce, pea, melon, and watermelon (Gao et al. 2004; Ling et al. 2009; Nicaise et al. 2003; Nieto et al. 2006; Ruffel et al. 2002, 2005). Recessive resistance is frequently attained when eIFs, which are essential for the potyviral cycle, are absent or carry amino acid substitutions resulting in incompatibility between viral factors and the eIF. In this respect, cucumber plants in which eIF4E was knocked out showed resistance to a broad spectrum of viruses (Chandrasekaran et al. 2016). In a similar manner, melon RNA interference lines with reduced eIF4E expression exhibited resistance to viral infection, including MWMV and the carmovirus melon necrotic spot virus (Rodríguez-Hernández et al. 2012).

In this article, we show data on the biological characterization of a Spanish MWMV isolate and the identification of potential sources of resistance to MWMV in Cucurbita spp. accessions, including PI 432441, a $C$. ecuadorensis accession. Our data suggest that PI 432441 resistance to MWMV may be controlled by two recessive genes. We also tested the hypothesis of the implication of $e I F 4 E$ in resistance control.

\section{MATERIALS AND METHODS}

Surveys and sample collection. Surveys were performed in open-field and greenhouse squash crops of the Murcia Province in 
Spain during 2009 and 2010. Samples were randomly collected from fields in two geographical areas as shown in Figure 1D.

Plant material. Evaluation of susceptibility to MWMV was carried out under experimental conditions for 24 Cucurbita spp. accessions (U.S. Department of Agriculture germplasm collection; see below) and 19 commercial squash (C. pepo) cultivars, including Negro Belleza (Semillas Fitó), Lucía (Intersemillas), Brillante (Semillas Fitó), Berula (Semillas Fitó), Alexander (Semillas Fitó), Espada (HM-Clause), Hobbit (Intersemillas), Pixar (Gautier), Cassiopee (Gautier), Yolanda (HM-Clause), SF-9423 (Semillas Fitó), Cora (HM-Clause), Amalia (Diamond Seeds), Taylor (Monsanto), Charlotte (Gautier), Skandia (Diamond Seeds), Amalthée (Gautier), Jedida (Semillas Fitó), and Kouros (Gautier). Parental susceptible $C$. pepo breeding line A-0501-6 used in the analysis of resistance inheritance was obtained from Semillas Fitó. F1 and F2 populations resulting from the cross between PI 432241 and A-0501-6 were also used in this study.

Virus inoculation and detection. MWMV-SQ10_1.1 was biologically cloned by four serial single necrotic lesion passages in healthy Chenopodium amaranticolor plants (Lecoq et al. 2008). After passage in Chenopodium amaranticolor, the virus was multiplied in squash cultivar Negro Belleza (Semillas Fitó). All virus inoculations were performed by rubbing recently expanded cotyledons (for cucurbits) or young but fully expanded leaves (for Chenopodium amaranticolor) with extracts from MWMV-infected squash plants and reinoculated 3 days later. Fifteen days after inoculation, leaf samples from each squash cultivar and Cucurbita spp. plants were tested with the standard double antibody sandwich (DAS) enzyme-linked immunosorbent assay (ELISA) using antiserum to MWMV according to the manufacturer's instructions (DSMZ GmbH). Average ELISA readings were calculated as a mean of two technical repeats. Symptoms in commercial squash cultivars were scored after 2 weeks postinoculation on a 0 to 4 scale as follows: 0 indicated an absence of symptoms, 1 indicated mild mosaic in the second leaf, with no symptoms in the third and fourth leaves; 2 indicated mosaic and vein clearing in the second leaf, with leaf bubbling in the third and fourth leaves; 3 indicated stunting, with mosaic, incipient necrosis, and/or vein clearing in the second leaf and leaf bubbling in the third and fourth leaves; and 4 indicated severe stunting, with mosaic, partial necrosis, and obvious vein clearing in the second leaf and leaf bubbling and vein banding in the third and fourth leaves.

RNA purification and sequence analysis. Total RNA was extracted from $40 \mathrm{mg}$ of infected squash leaves with TRIzol Reagent (Thermo Fisher). cDNA was synthesized with Expand Reverse Transcriptase (Roche) using two different primers: a poly (dT) and a second primer (5'-GTATGTCGCTAGCTACAATG-3') at position $4,000 \mathrm{bp}$ that is conserved in all MWMV isolates. Polymerase chain reaction (PCR) for amplification was performed with Primer Star HS DNA (Takara, Clontech). The complete genome of MWMV Sq10_1.1 was determined by sequencing in both directions overlapping PCR fragments obtained with primers designed in conserved regions as follows: CE2023 (5'-AAAT AAAACATCTCAACACAAC-3'), CE2024 (5'-TTGAATCTAAC TGAAGCAAG-3'), CE2025 (5'-GGAACACACCTTCTTCGAA G-3'), CE2026 (5'-AGACTCTAAATGCACGAAACG-3'), CE2027

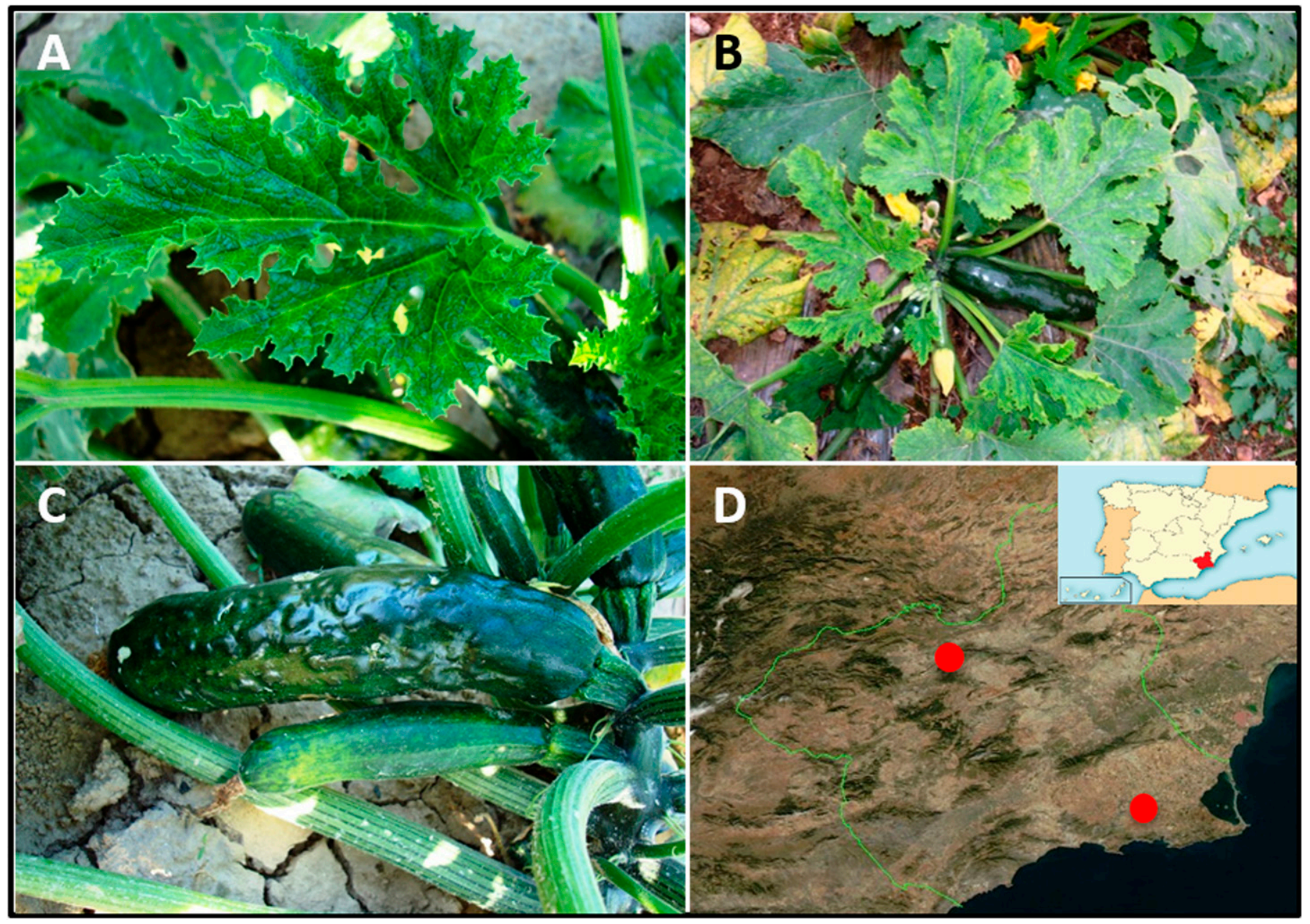

Fig. 1. Field-grown squash plants showing severe virus-like symptoms in Murcia, Spain. A, Symptoms in leaves, B, stunting, and $\mathbf{C}$, pronounced fruit malformations. D, Areas surveyed in Murcia, Spain, during 2009 and 2010. 
(5'-ACGATCGCCCTTTGAGTAAG-3'), CE2028 (5'-ATTTGCT CGTGATCCGCTTG-3'), CE2029 (5'-AAGTTAAAGGTTGCA GTTG-3'), CE2030 (5'-AAGCGAGTTTCTCAAATTTG-3'), CE2031 (5'-GTCGGAAGTGGTAAGTCAAC-3'), CE2032 (5'-GTATG
TCGCTAGCTACAATG-3'), CE2033 (5'-GCTAGAACAATGCT ACATTTTGAAC-3'), CE2034 (5'-GTCGCGTTACATGATCGAT C-3'), CE2035 (5'-TCAACTTACGGATTTAAGCC-3'), CE2036 (5'-GGCATAGGTTACAATTCATA-3'), CE2037 (5' -AATGAAA

A
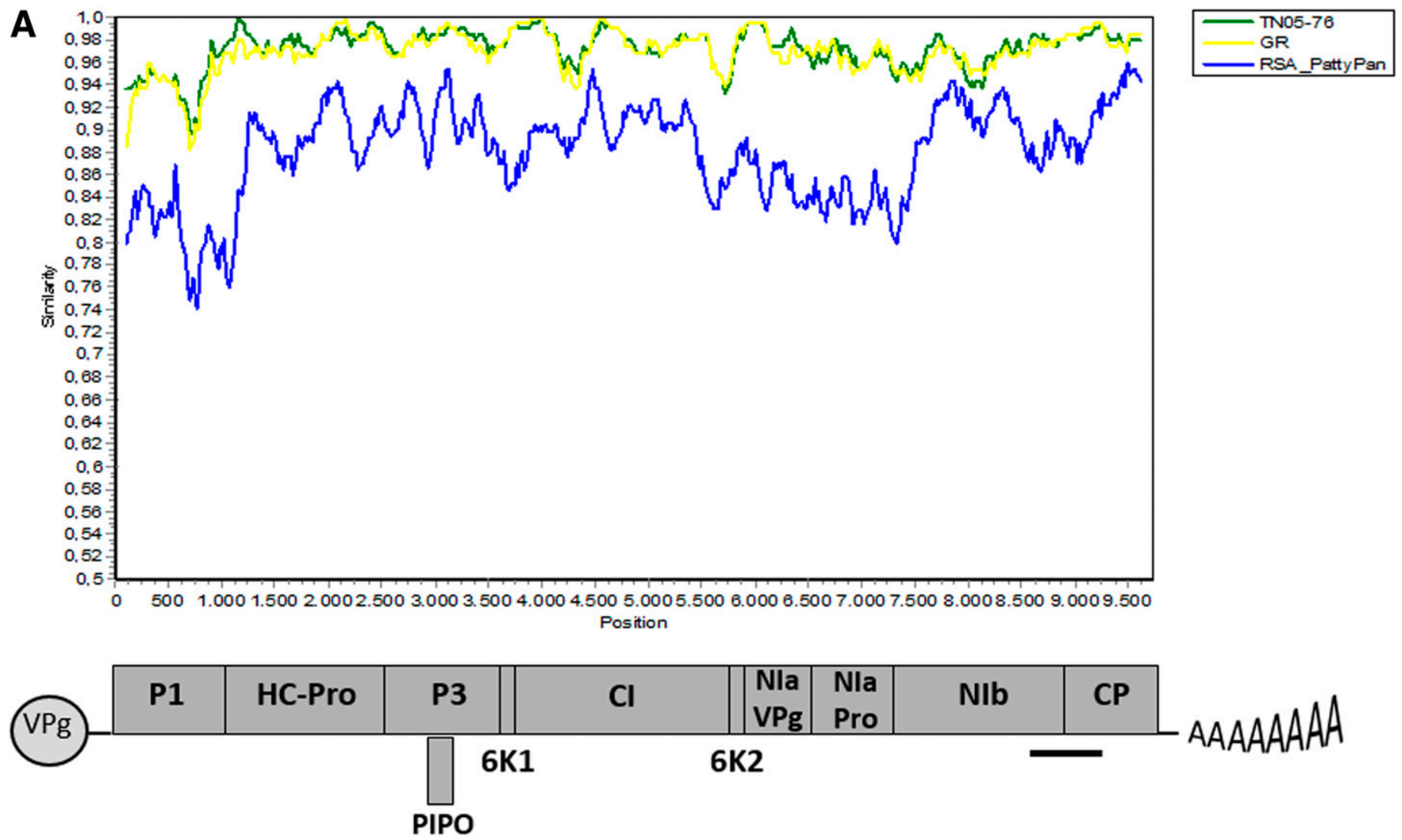

B

72 MWMV TN05-73
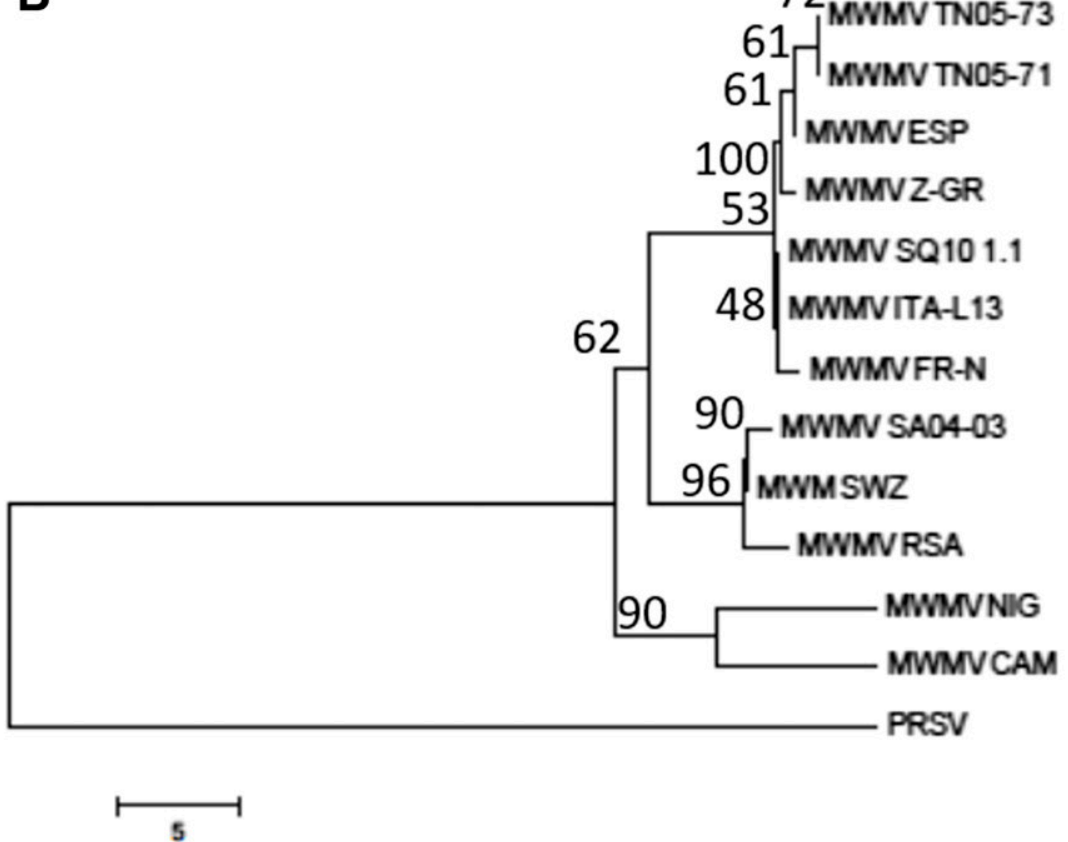

Fig. 2. Sequencing of the genomic RNA of MWMV-SQ10_1.1. A, Nucleotide sequence similarity plot (performed with SimPlot software; Lole et al. 1999), comparing nucleotide sequences of Moroccan watermelon mosaic virus (MWMV) TN05-76, GR, and RSA pattypan isolates (accession numbers NC_009995, EF579955, and KU315176, respectively) versus MWMV-SQ10_1.1. Each point plotted is the percent identity within a sliding window 500 bp wide centered on the position of the plotted point, with a step size between points of $20 \mathrm{bp}$. The diagram below the plot is a cartoon representation of the MWMV genomic structure with the open reading frames represented in open boxes. B, Neighbor-joining tree constructed based on amino acid sequences from the C-terminal part of the polymerase and N-terminal part of the coat protein of $12 \mathrm{MWMV}$ isolates and papaya ringspot virus (PRSV) as the outgroup. Bootstrap analysis was applied using 1,000 bootstrap replicates (percentage shown near the nodes). The Genbank accession numbers are EF579950, EF579949, EF579948, EF579947, EF579946, EF579945, EF579944, EF579943, EF579942, KF772944, KU315176, and NC001785. 
TCAGTTGGGGAAG-3'), CE2038 (5'-AAGCGAAAGTATTTTG AAGG-3'), CE2039 (5'-CCATCATCAAGAAATTTAAGGG-3'), CE2040 (5'- GACTTAGCTTTGAAGGGTAA-3'), CE2041 (5' TGACTATGGTCTTGATGATG-3'), CE2042 (5'-GTGAAGTCT CGGTTTTAACC-3'), CE2043 (5'-TTTTTCTCTCACTATGAGT TAC-3'), CE2044 (5'-GCTATGCCAGCTTTGTGTCTTCC-3'), CE2045 (5'-CATTTCAGACACCTCCTGATC-3'), CE2046 (5'-T

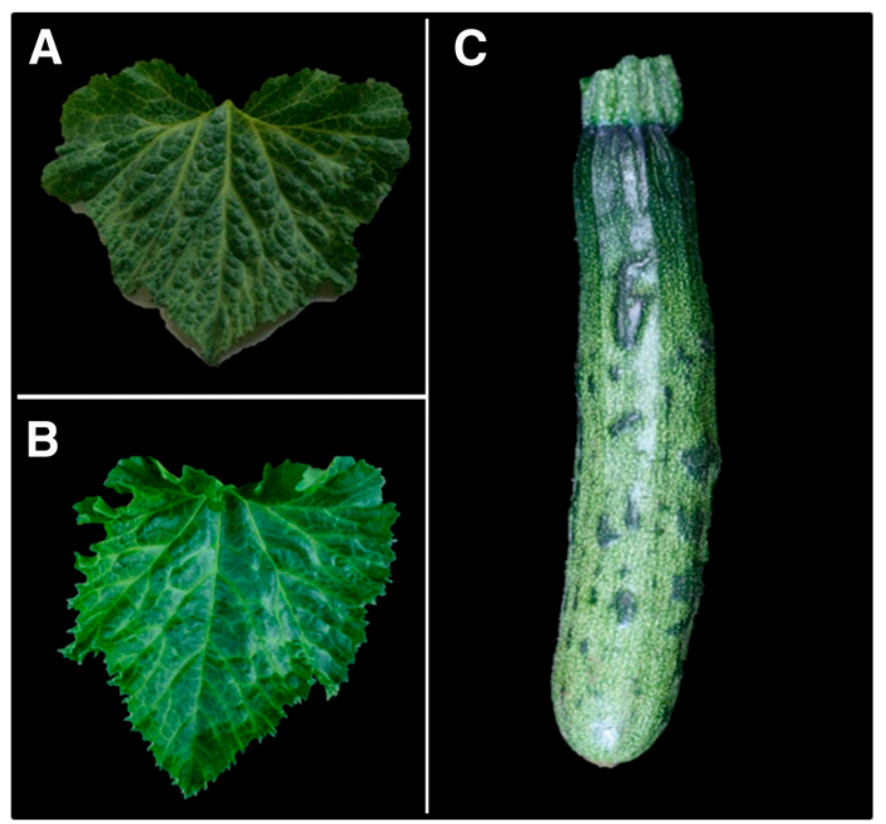

Fig. 3. Moroccan watermelon mosaic virus (MWMV)-induced symptoms in squash cultivars. A, Marked leaf bubbling and B, vein clearing and vein banding induced by MWMV-SQ10_1.1 by 11 to 14 days postinoculation. C, Plants infected with MWMV-SQ10_1.1 hardly produced any fruit; in the few cases where fruits set and grew, they showed severe symptoms, including mosaics and malformations.

TABLE 1. Moroccan watermelon mosaic virus (MWMV) symptom severity in commercial squash cultivars

\begin{tabular}{lc}
\hline Cultivar $^{\mathrm{a}}$ & ${\text { Symptom severity } \text { score }^{\mathrm{b}}}^{\text {Berula }}$ \\
Alexander & $3.5 \pm 0.3$ \\
SF-9423 & $3.5 \pm 0.2$ \\
Espada & $3.5 \pm 0.6$ \\
Hobbit & $3.5 \pm 0.5$ \\
Yolanda & $3.7 \pm 0.4$ \\
Negro Belleza & $3.5 \pm 0.3$ \\
Cassiopee & $4.0 \pm 0.2$ \\
Pixar & $3.8 \pm 0.4$ \\
Lucía & $3.8 \pm 0.2$ \\
Cora & $4.0 \pm 0.1$ \\
Amalia & $3.5 \pm 0.3$ \\
Taylor & $3.5 \pm 0.3$ \\
Brillante & $3.5 \pm 0.2$ \\
Charlotte & $3.0 \pm 0.2$ \\
Skandia & $3.5 \pm 0.4$ \\
Amalthée & $3.5 \pm 0.3$ \\
Jedida & $3.5 \pm 0.5$ \\
Kouros & $3.5 \pm 0.4$ \\
\hline
\end{tabular}

a Twelve plants per cultivar were inoculated with MWMV at the cotyledonary stage. b Symptom severity was estimated based on a 0 to 4 scale at 14 days postinoculation. By this time, plants had four expanded leaves, which were numbered from bottom to top. The scores were as follows: 0 indicated an absence of symptoms; 1 indicated mild leaf bubbling in leaves 1 and 2, with an absence of symptoms in leaves 3 and 4; 2 indicated leaf bubbling in all leaves; 3 indicated leaf bubbling and vein banding in all leaves, with silvering of leaf 2 ; and 4 indicated marked leaf bubbling and vein banding in all leaves and incipient necrosis in leaves 1 and 2 . Symptom severity scores are presented as means of the score of 12 plants \pm SD.
TACACAACTGCAAACGTGAAC-3'), CE2047 (5'-CATCGTTC CATCAGGTGCAAC-3'), and CE2048 (5'-TTCCTTGACAATTC TGAATGGC-3'). The sequence of the genomic RNA of MWMV SQ10_1.1 determined here is available in GenBank (accession number KY762266).

Inheritance of MWMV resistance in PI432441. The inheritance mode of PI 432241 resistance to MWMV was studied in a genetic family composed of PI 432241 (six plants), the susceptible breeding line A-0501-6 (five plants), and their F1 (14 plants) and F2 (156 plants) progenies. Plants were inoculated as described above and were analyzed with DAS-ELISA at 15 days postinoculation (dpi). Samples were considered positive when the absorbance values were greater than three times the average value for healthy control samples. The $\chi^{2}$ test was performed to test the goodness of fit of the F2 population for the phenotypic data by comparing the observed frequency distribution with an expected frequency distribution.

Amplification and sequence analysis of eIF4E. RNA from Cucurbita spp. accessions was extracted as described above and cDNA was synthesized with Expand Reverse Transcriptase (Roche) using a poly(dT) primer. Based on the conservation among Cucumis sativus and Cucumis melo eIF4E sequences, two primers were designed flanking the coding sequence region for amplification: CE763 (5'-CCATTGATTCGATTCTTCAG-3') and CE764 (5'AGGACGAGTTATCCTCCTCC-3'). PCR products were cleaned up by MEGAquick-spin columns (Labotaq) and three independent PCRs were directly sequenced with primer CE763.

The three-dimensional structure of PI 432441 eIF4E was generated by the I-TASSER server (Roy et al. 2010) using the C. melo eIF4E structure as a template (Miras et al. 2017).

Development of allele-specific markers. A web-based allele-specific (AS) PCR assay was used to detect single nucleotide polymorphisms (SNPs) in eIF4E alleles (Wangkumhang et al. 2007). Because of the high conservation of the eIF4E nucleotide sequence shown between parental lines, four different AS-PCR primers were designed to detect SNPs in the first exon. To improve reaction specificity, mismatches at the penultimate base of the AS primer were introduced. The common and nonspecific allele primer was designed at the beginning of the coding sequence as follows: CE2386 (5'-ATGGTAGTCGAAGAGACGATCAA-3'). AS primers to detect CpeIF4E1 (CE2387: 5'-CGATAAATTGGAGGAG TCCCA-3'), CpeIF4E2 (CE2388: 5'-CAAGTCCTCATCTTCCTC AGCG-3'), CeeIF4E1 (CE2389: 5'-GGATAGACGCACCCCAGG TGGTT-3'), and CeeIF4E2 (CE2390: 5'-CCAGAAGGTCCAAG AGTGCTCCAAT-3') generated 130, 94, 237, and 186 bp amplicons, respectively. Each PCR mixture contained $20 \mathrm{ng}$ of DNA, $5 \mu \mathrm{l}$ of $5 \times$ PCR buffer, $2 \mu \mathrm{l}$ of $10 \mathrm{mM}$ dNTPs, and $1 \mathrm{U}$ of PrimeStar (Takara). PCR amplification conditions were an initial denaturing step of $94^{\circ} \mathrm{C}$ for $2 \mathrm{~min} ; 30$ cycles of $94^{\circ} \mathrm{C}$ for $30 \mathrm{~s}, 60^{\circ} \mathrm{C}$ for $15 \mathrm{~s}$, and $72^{\circ} \mathrm{C}$ for $15 \mathrm{~s}$; and a final extension step of $72^{\circ} \mathrm{C}$ for $5 \mathrm{~min}$. The PCR products were electrophoresed on $1.5 \%$ agarose gels.

\section{RESULTS}

Epidemics of MWMV and WMV-Em in squash in Spain. In late spring 2009, field-grown squash plants showing severe mosaics in leaves (Fig. 1A), stunting (Fig. 1B), and striking fruit malformations (Fig. 1C) were observed near San Javier in Campo de Cartagena, Murcia, Spain. Symptoms resembled those caused by potyviruses but looked more severe than usual. Later, during fall 2009 and spring 2010, squash crops grown in greenhouses or open fields in the same or other areas of the Murcia province (Fig. 1D) showed similar symptoms. MWMV, WMV, or both were consistently detected in symptomatic samples by standard DAS-ELISA. Reverse transcription (RT)-PCR amplification of cDNA fragments from 10 independent samples corresponding to approximately 800 nt of the CI cistron of WMV or MWMV was performed; seven and five samples were positive for MWMV or WMV, respectively, and 
two samples were positive for both viruses. RT-PCR fragments were cloned in Escherichia coli and sequenced, showing 96\% nucleotide sequence identity with MWMV-TN05-76 and 98\% with WMVFBR04-37 (emergent type; WMV-Em) sequences. Surveys during 2010 and 2011 showed that MWMV and WMV-Em cocirculate in epidemics in squash in southeastern Spain (unpublished data) and WMV-Em was consistently detected in diseased watermelon and melon plants sampled in the same area (Juárez et al. 2013a). Therefore, both MWMV and WMV-Em seem to represent a significant threat for cucurbit crops in this region. WMV has been extensively studied, whereas information on the biology of MWMV is scant. Thus, we focused on MWMV for the following experiments.

MWMV causes severe disease in squash. Biological cloning of MWMV was performed, taking advantage of the specific local lesion host Chenopodium amaranticolor. The near complete genomic RNA sequence of the cloned isolate MWMV-SQ10_1.1 was determined; its genomic structure is similar to that of other potyviruses (Fig. 2A). Comparative genomic analyses showed high nucleotide similarity to isolates MWMV-TN05-76 and MWMVGR (>97\%) (Fig. 2A) from Tunisia and Greece, respectively, and low nucleotide similarity to the isolate MWMV-RSA (89\%) from South Africa. A phylogenetic analysis including isolates for which sufficient sequence data are available, comprising the amino acid sequences of the contiguous $\mathrm{C}$-terminal part of the nuclear inclusion $\mathrm{b}$ protein and the $\mathrm{N}$ terminus of the coat protein (marked in Fig. 2A), was performed. The analysis showed three genetic groups: clade A, with isolates from Tunisia and Europe, which includes MWMVSQ10_1.1; clade B, with isolates from South Africa; and clade C with isolates from Central Africa (Fig. 2B). We then tested the ability of MWMV-SQ10_1 to infect and cause symptoms in a collection of commercial squash cultivars, including some described as resistant to potyviruses (Supplementary Fig. S1). All inoculated plants from all cultivars showed symptoms at 7 to 10 dpi. By 11 to $14 \mathrm{dpi}$, symptoms were severe and included marked leaf bubbling (Fig. 3A), vein clearing and vein banding (Fig. 3B), leaf silvering, and incipient necrosis. Plants hardly produced any fruit, but in the few cases in which fruits grew, they showed severe infection symptoms, including mosaics and malformations
(Fig. 3C). MWMV symptom severity was assessed according to symptom severity scale at $14 \mathrm{dpi}$, with scores ranging from 0 to 4 . The average symptom severity was 3.6, with a maximum of 4 for cultivars Lucía and Negro Belleza and a minimum of 3 for cultivar Brillante (Table 1).

Susceptibility of Cucurbita spp. accessions to MWMV. Twenty-four Cucurbita spp. accessions were tested for their susceptibility to MWMV-SQ10_1, including C. pepo, C. ecuadorensis, C. foetidissima, and C. moschata species (Table 2) in an attempt to cover a broad range of diversity with a small collection. Different infection phenotypes were identified. All C. pepo accessions showed clear infection symptoms and high virus titers and were classified as fully susceptible. Most $C$. foetidissima and all C. moschata accessions accumulated the virus to a level comparable to susceptible controls but did not show symptoms, and they were classified as tolerant. All C. ecuadorensis accessions and one C. foetidissima accession showed no or low virus titer compared with susceptible controls and did not show symptoms, and they were classified as resistant or partially resistant. Finally, two C. foetidissima accessions consistently showed fully infected (although asymptomatic) plants together with noninfected plants,

TABLE 3. Segregation of the character "ELISA reading for Moroccan mosaic virus" in progenies of the cross between PI 432441 and A-0501-6

\begin{tabular}{lcccc}
\hline $\begin{array}{l}\text { Tested } \\
\text { population }\end{array}$ & $\begin{array}{c}\text { Observed } \\
\text { segregation (R:S) }\end{array}$ & $\begin{array}{c}\text { Expected } \\
\text { ratio (R:S) }\end{array}$ & $\chi^{2}$ value & $P$ value \\
\hline Parent & & & & \\
$\quad$ A-0501-6 & $0: 10$ & $0: 1$ & & \\
$\quad$ PI 432441 & $7: 0$ & $1: 0$ & & \\
Progeny & $0: 14$ & $0: 1$ & & \\
$\quad$ F1 & $11: 146$ & $1: 15$ & 0.00683 & 0.9342 \\
F2 &
\end{tabular}

${ }^{a} \mathrm{R}=$ resistant plant (enzyme-linked immunosorbent assay [ELISA] readings at 15 days postinoculation [dpi] $<3$ times the averaged values of healthy control samples), and $\mathrm{S}=$ susceptible plant (ELISA readings at $15 \mathrm{dpi} \geq 3$ times the averaged values of healthy control samples).

TABLE 2. Susceptibility of Cucurbita spp. accessions to Moroccan mosaic virus

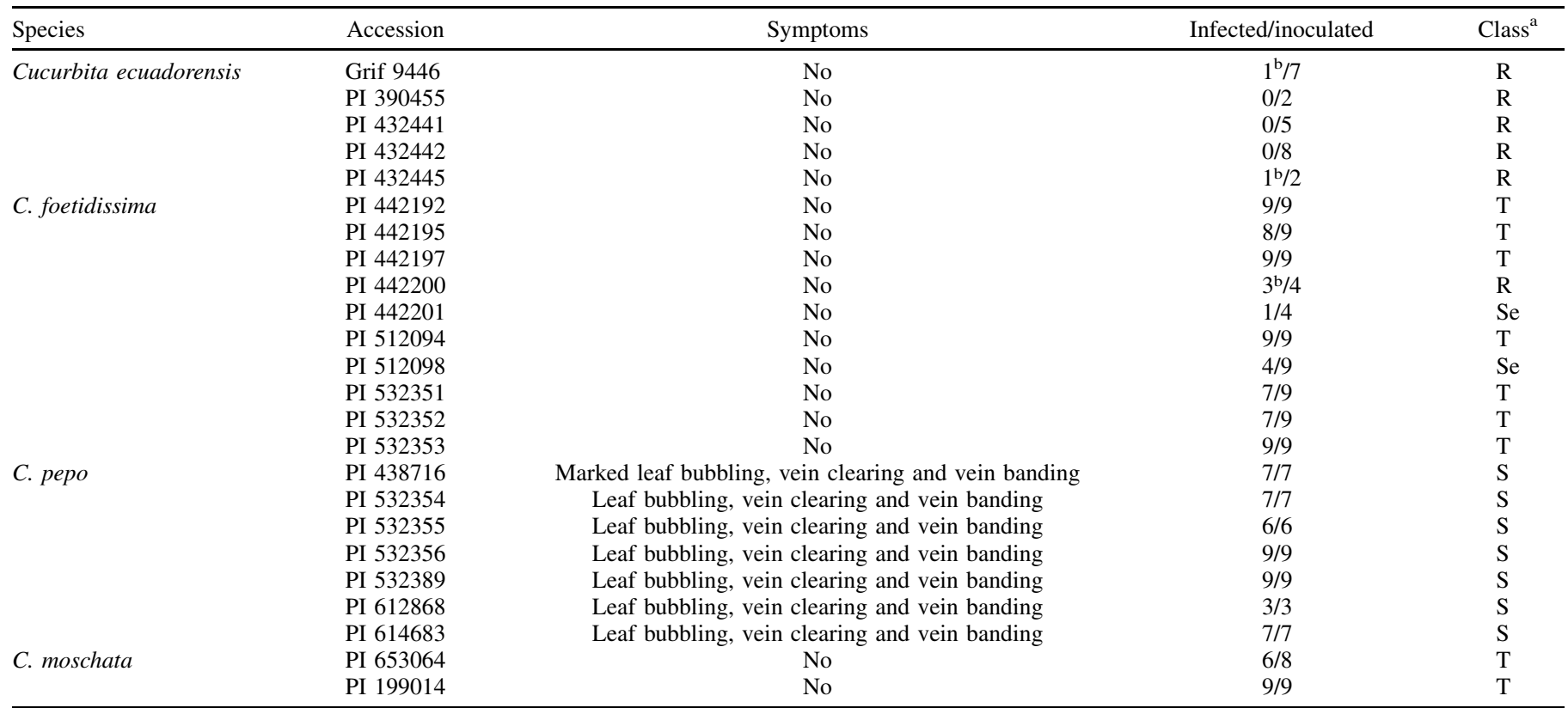

${ }^{a} \mathrm{~S}=$ susceptible plant (enzyme-linked immunosorbent assay [ELISA] readings at 15 days postinoculation [dpi] $>3$ times the averaged values of healthy control samples), $\mathrm{T}=$ tolerant plant (no symptoms but ELISA readings at $15 \mathrm{dpi}>3$ times the averaged values of healthy control samples), $\mathrm{R}=$ resistant plant (ELISA readings at $15 \mathrm{dpi}<3$ times the averaged values of healthy control samples), and $\mathrm{Se}=$ phenotypic segregation (fully infected together with noninfected plants).

b This plant had ELISA readings significantly smaller than the averaged values of susceptible infected controls. 
and they were provisionally classified as segregating (Table 2; Supplementary Fig. S2).

Inheritance of MWMV resistance in $C$. ecuadorensis accession PI 432441. Squash breeding line A-0501-6 is fully susceptible to MWMV. Plants of the PI 432441 C. ecuadorensis accession were crossed with plants of the A-0501-6 line to obtain the F1 and, subsequently, F2 corresponding progenies. Resistance in parental, F1, and F2 populations was studied based on systemic accumulation of MWMV at $15 \mathrm{dpi}$ as estimated by ELISA readings. All A-0501-6 plants showed evident symptoms at 15 dpi (Supplementary Fig. S3) and, with an average ELISA reading in this cultivar of $2.457 \pm 0.119$, these plants were scored as susceptible. PI 432441 plants showed no symptoms, and their ELISA readings were similar to those of the negative, noninoculated controls; these plants were scored as resistant. F1 plants showed a behavior essentially similar to A-0501-6, with ELISA readings averaging $2.126 \pm 0.678$, indicating the recessive nature of the resistance
(Supplementary Table S1). F2 plants showed segregation for resistance. F2 segregation fit the ratio $1 \mathrm{R}: 15 \mathrm{~S}\left(\chi^{2}=0.00683, P=\right.$ $0.93)$, which suggests that two recessive genes control the resistance to MWMV in PI 432441 (Table 3).

Do eIF4E alleles cosegregate with PI 432441 resistance to MWMV? We hypothesized that PI 432441 resistance to MWMV could be associated with eIF4E, particularly after determination of its recessive nature and also based on previous results from knocked-down $e I F 4 E$ melon lines that were resistant to this virus (Rodríguez-Hernández et al. 2012). A search in the C. pepo genome (Montero-Pau et al. 2018) revealed the existence of two eIF4E orthologs, named CpeIF4E1 and CpeIF4E2. Using this information, specific primers were designed to amplify by RT-PCR cDNAs for the two $C$. ecuadorensis eIF4E paralogs, designated here as CeeIF4E1 and CeeIF4E2. The eIF4E-deduced amino acid sequences showed high identity $(>97 \%)$ with their corresponding C. pepo eIF4E alleles. A multiple sequence alignment, including

A

CeeIF4E1

CeeIF4E2

CpeIF4E1

CpeIF4E2

Watermelon

Pepper

Pea

CeeIF4E1

CeeIF4E2

CpeIF4E1

CpeIF4E2

Watermelon

Pepper

Pea

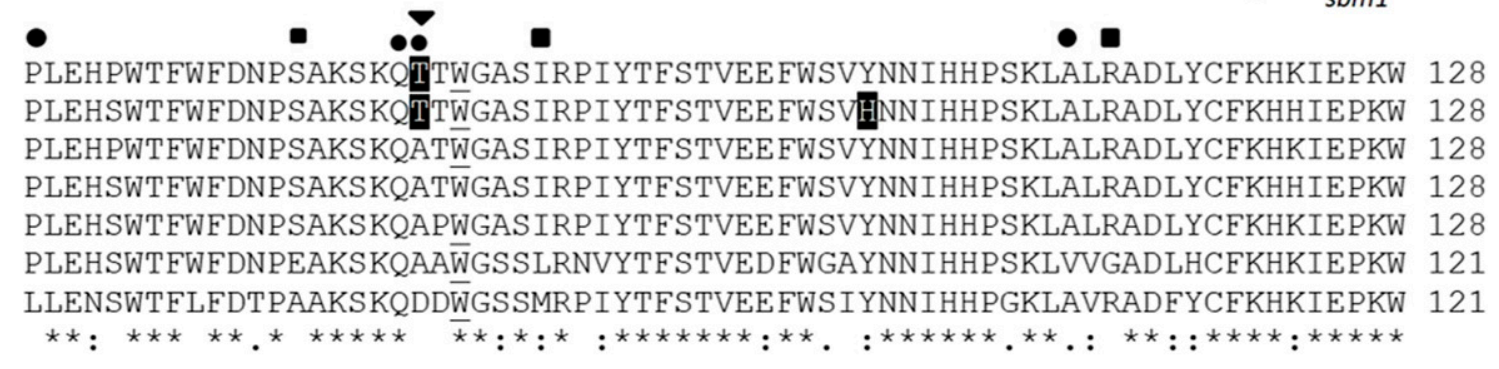

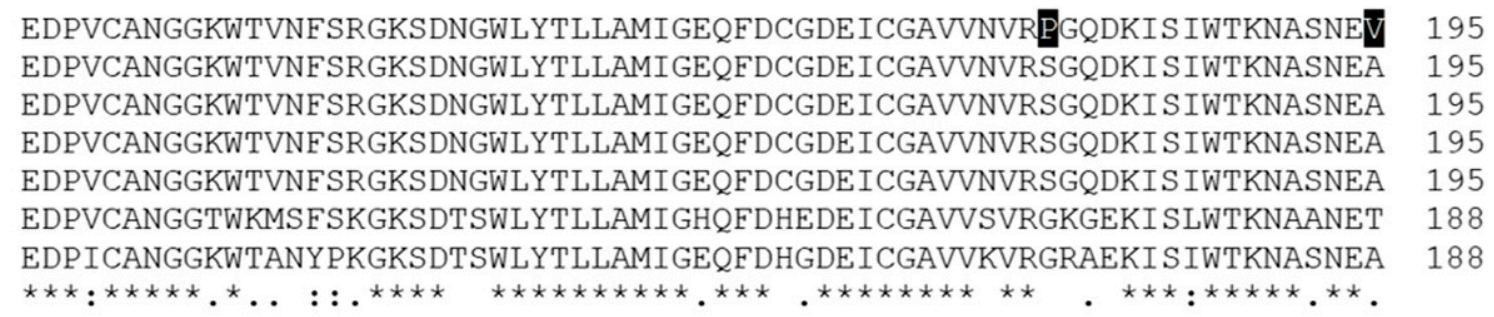

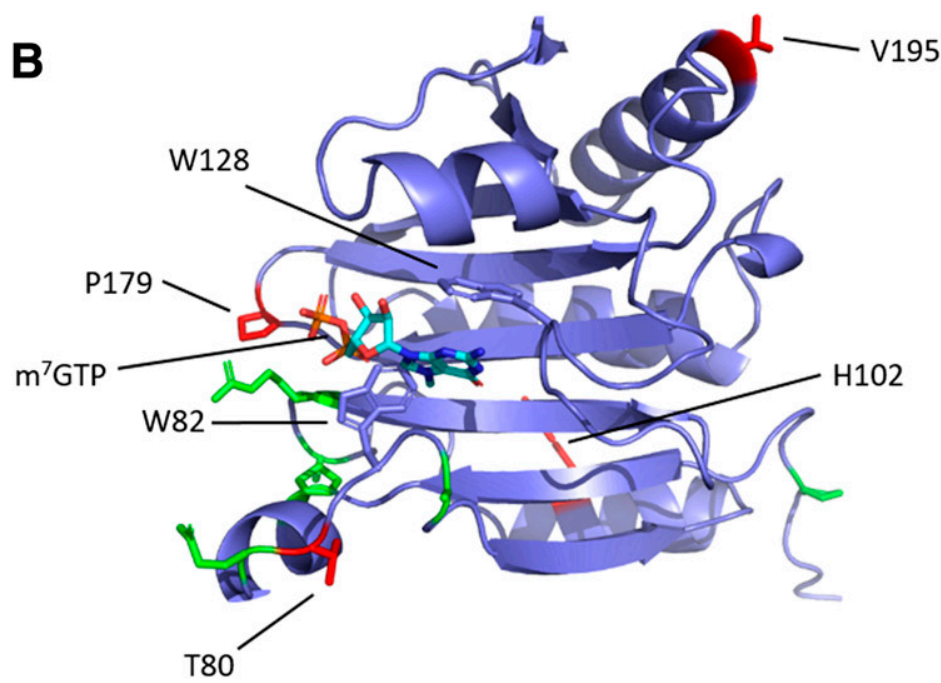

Fig. 4. Potyvirus resistance and eukaryotic translation initiation factor $4 \mathrm{E}$ (eIF4E). A, Amino acid sequence alignment of eIF4E from Cucurbita ecuadorensis accession PI 432441 (CeeIF4E1 and CeeIF4E2), C. реро (CpeIF4E1 and CpeIF4E2), and eIF4E resistance alleles against potyviral infection in other plant species. Amino acid substitutions in the eIF4E alleles of PI 432441 in T80, P179, and V195 of CeeIF4E1 and T80 and H102 of CeeIF4E2 are shaded in black. Watermelon, pepper ( $p v r 2$ ), and pea ( $s b m 1)$ eIF4E resistance alleles confer resistance to zucchini mosaic virus (ZYMV), potato virus Y (PVY), and pea seed-borne mosaic virus (PSbMV), respectively, and the corresponding substitutions are marked with symbols as shown in the legend. Tryptophan (W) involved in cap binding is underlined. B, Predicted three-dimensional structure of consensus eIF4E sequence from PI 432441 based on the melon eIF4E crystal structure (Miras et al. 2017) with T80, H102, P179, and V195 substitutions marked in red and shown as sticks. In green are amino acids described in watermelon, pepper, and pea eIF4E to confer resistance to potyviruses. Tryptophans W82 and W128 interacting with the $\mathrm{m}^{7} \mathrm{GTP}$ Guanosine-5'-triphosphate cap analog are shown as sticks. 
sequences from known potyvirus resistance $e I F 4 E$ alleles, identified three amino acid substitutions (T80, P179, and V195) in CeeIF4E1 and two amino acid substitutions (T80 and H102) in CeeIF4E2 that could potentially be implicated in potyvirus resistance (Fig. 4A). Interestingly, the substitution in position 80 in both CeeIF4E1 and CeeIF4E2 is located in the eIF4E cap-binding pocket (Miras et al. 2017). In other plant species, similar mutations in eIF4E were shown to confer resistance to potyvirus infection (Fig. 4B).
We then developed markers to distinguish between the four eIF4E alleles, taking advantage of the AS-PCR method, and we set up a multiplex-PCR in which markers are simultaneously amplified in the same reaction (Wangkumhang et al. 2007). This method is based on the extension of the primer only when its $3^{\prime}$ end matches perfectly to the allele present in the input sample. Thus, heterozygous plants are also detected. Specific-allele primers were designed to distinguish the $\mathrm{A} \rightarrow \mathrm{G}$ polymorphism at position 237 in CeeIF4E1
A

CeeIF4E1
CpeIf4E1
CeeIF4E2
CpeIF4E2

CeeIF4E1

CpeIF4E1

CeeIF4E2

CpeIF4E2

CeeIF4E1

CpeIF4E1

CeeIF4E2

CPeIF4E2

CeeIF4E1

CPeIF4E1

CeeIF4E2

CpeIF4E2

Fns

ATGGTAGTCGAAGAGACGATCAAAGCTACATCGATGGAAGATCTTTCTAATTCCATCGCA ATGGTAGTCGAAGAGACGATCAAAGCTACATCGATGGAAGATCTTTCTAATTCCATCGCA ATGGTAGTCGAAGAGACGATCAAGGCTCCATCGGCGGAAGATCTCTCCAATTCCATTGGA ATGGTAGTCGAAGAGACGATCAAGGCTCCATCGGCGGAAGATCTCTCCAATTCCATTGGA

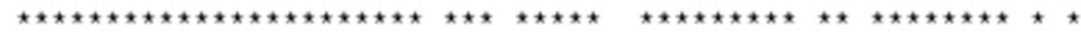
AS-4 AATCAAAACCCTAGGGGACGAGGCAATGAGGAAGATGAGGATCTTGAGGAAGGAGAGATC AATCAAAACCCTAGGGGACGAGGCAATGAGGAAGATGAGGATCTTGAGGAAGGAGAGATC AATCAAAACCCTAGGGGACGAGGTGTGAGGAAGATGAGGAACTTGAGGAAGGAGAGATC AATCAAAACCCTAGGGGACGAGGCGCTGAGGAAGATGAGGAACTTGAGGAAGGAGAGATC

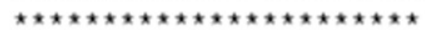

AS-3 GTCGGCGACGACGACCTGGACTCCTCCAATTTATCGGCGGCGATAGTGCATCAGCCTCAC GTCGGCGACOACGACTTGGACTCCTCCAATTTATCGGCAGCGATAGTGCATCAGCCTCAC GTCGGCGCCGACGACCTCGACGCGTCCAATTTATCGGCGGCGATAGTGCACCAGCCTCAC GTCGGCGCCGACGACCTCGACGCGTCCAATTTATCGGCGGCGATAGTGCACCAGCCTCAC

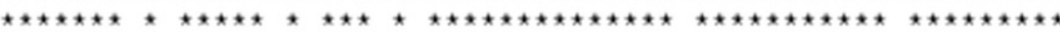
CCTCTGGAGCACCCTTGGACCTTTTGGTTCGATAACCCATCCGCCAAGTCCAAGCAAACC CCTCTGGAGCACCCTTGGACTTTTTGGTTCGATAACCCATCCGCCAÄTCCAAGCAGGCC CCATTGGAGCACTCTTGGACCTTCTGGTTCGATAACCCTTCTGCCAAATCTAAACAGACC CCTCTGGAGCACTCTTGGACCTTCTGGTTCGATAACCCTTCTGCCAAATCTAAACAGGCC

60 60 60 60

B

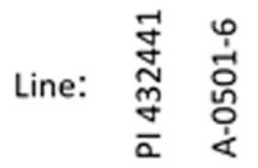
F2

\begin{tabular}{|c|c|c|c|c|c|c|c|c|c|c|c|c|c|c|c|c|c|c|c|c|}
\hline Plant & 1 & 2 & 3 & 4 & 5 & 6 & 7 & 8 & 9 & 10 & 11 & 12 & 13 & 14 & 15 & 16 & 17 & 18 & 19 & 20 \\
\hline Phenotype & $\mathbf{R}$ & $s$ & $\mathbf{R}$ & $\mathbf{R}$ & $\mathbf{R}$ & $\mathbf{R}$ & $\mathbf{R}$ & $s$ & $s$ & $s$ & $s$ & $s$ & $s$ & $s$ & $s$ & $s$ & $s$ & $s$ & $s$ & s \\
\hline CeelF4E1 & $\mathrm{x}$ & & & $x$ & & $x$ & $x$ & & $x$ & $x$ & & $\mathrm{x}$ & $x$ & $x$ & $\mathrm{x}$ & $x$ & $x$ & $x$ & $x$ & $x$ \\
\hline CeelF4E2 & $\mathrm{x}$ & & $\mathrm{x}$ & $\mathrm{x}$ & $\mathrm{x}$ & $\mathrm{x}$ & $\mathrm{x}$ & $\mathrm{x}$ & & & $\mathrm{x}$ & & & & & & & & & \\
\hline Cpelf4E1 & & $x$ & $\mathrm{x}$ & & $x$ & & & $\mathrm{x}$ & & & $x$ & $x$ & $x$ & $\mathrm{x}$ & & & $x$ & & $x$ & \\
\hline CpelF4E2 & & $\mathrm{x}$ & & & & $x$ & & $\mathrm{x}$ & $x$ & $x$ & $x$ & & $x$ & $x$ & $\mathrm{x}$ & $x$ & $x$ & $x$ & $x$ & $x$ \\
\hline
\end{tabular}
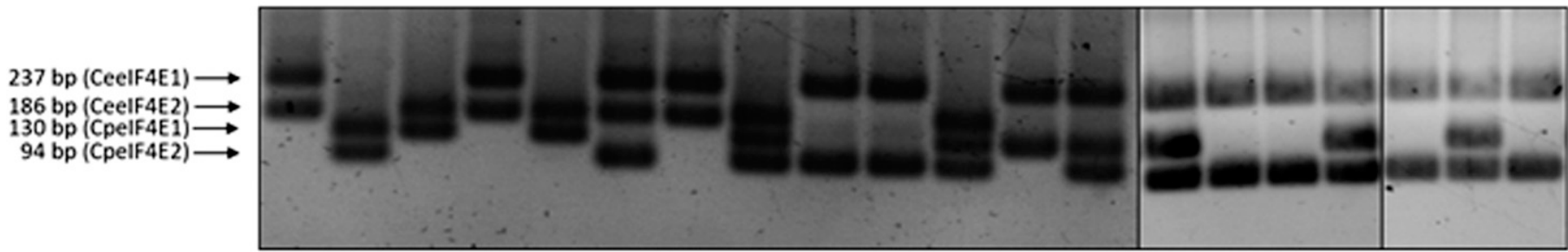

Fig. 5. Design of markers in the eukaryotic translation initiation factor $4 \mathrm{E}$ (eIF4E) sequence. A, Nucleotide sequence alignment of the $5^{\prime}$ end of $e I F 4 E$ coding sequences of alleles from Cucurbita ecuadorensis (CeeIF4E1 and CeeIF4E2) and C. pepo (CpeIF4E1 and CpeIF4E2). The identified single nucleotide polymorphisms (SNPs) are shaded in black and the primers designed for the allele-specific (AS) polymerase chain reaction (PCR) assay are indicated by arrows (Fns: nonspecific, AS1, AS2, AS3, and AS4). B, Example of an agarose gel electrophoresis of SNP genotyping of F2 progeny (plants 3 to 20) together with parental lines PI 432441 and A-0501-6 (plants 1 and 2, respectively). The table above the image indicates the phenotype and genotype of each of the plants included. The susceptibility phenotype $(\mathrm{R}=$ resistance, $\mathrm{S}$ = susceptible) to Moroccan watermelon mosaic virus was determined based on enzyme-linked immunosorbent assay readings. The amplification of each allele is marked with an " $\mathrm{X}$ " (blank means no amplification). The size of the PCR products is indicated on the left. 
(AS-1), the AT $\rightarrow$ TC polymorphism at positions 185 and 186 in CeeIF4E2 (AS-2), the $\mathrm{C} \rightarrow \mathrm{G}$ polymorphism at position 130 in CpeIF4E1 (AS-3), and the $\mathrm{T} \rightarrow \mathrm{C}$ polymorphism at position 94 in CpeIF4E2 (AS-4) (Fig. 5A). Multiplex-PCR with the markers in PI 432441 resulted in the amplification of only two DNA products of 237 and $186 \mathrm{bp}$, corresponding to AS-1 and AS-2 markers (Fig. 5B, plant 1), whereas two bands at 130 and $94 \mathrm{bp}$ were produced in susceptible A-0501-6, corresponding to AS-3 and AS-4 markers (Fig. 5B, plant 2). When the entire F2 population was analyzed with the AS markers, only the CeeIF4E2 allele was present in all MWMV-resistant plants (Fig. 5B, plants 3 to 7), suggesting its implication in resistance; however, one resistant plant was heterozygous in the eIF4E2 locus (Fig. 5B, plant 6). Thus, assuming the recessive nature of the resistance, our results do not support an association of either CeeIF4E2 or CeeIF4E1 with this phenotype. The analysis of MWMV-susceptible samples resulted in the amplification of CpeIF4E and CeeIF4E alleles in different combinations (Fig. 5, lanes 8 to 20).

\section{DISCUSSION}

MWMV represents an important threat to cucurbit crops in the Mediterranean Basin and Africa. MWMV was described for the first time in the Iberian Peninsula in 2013 (Juárez et al. 2013b), but it was probably present in this area before that date and was likely masked by infections with other potyviruses, principally WMVEm, which also induces severe disease symptoms in squash. WMVEm has substituted the classical strain in WMV populations of southern France and Southeast Spain (Desbiez et al. 2009; Juárez et al. 2013a, 2013b). The data shown here and our unpublished results suggest that MWMV is quite well represented in potyvirus populations affecting cucurbit crops of Southeast Spain, particularly in squash crops. The Spanish isolate that we cloned and sequenced showed the typical potyvirus genome structure and was phylogenetically close to MWMV isolates from the Middle East, suggesting a common origin for MWMV isolates affecting Mediterranean crops. Using this isolate, we tested the susceptibility of a range of squash cultivars, including those commercialized as "potyvirus resistant." All cultivars were fully susceptible to MWMV, but there were slight differences in terms of disease severity; this may represent some help for growers when facing disease control, although resistant varieties are clearly needed. Aphid control is well implemented in commercial crops in Southeast Spain but in spite of this, potyvirus epidemic outbreaks take place often, and sporadically infected plants are detected particularly in the borders of the cultivation plots. Under these circumstances, the use of resistant cultivars is the best option for MWMV control. Several sources of resistance have been identified for MWMV, but all of them have outside species crossability with C. pepo. Thus, in this work we sought to screen Cucurbita spp. accessions to identify sources of resistance to MWMV within the genus Cucurbita. The number of accessions we tested was rather limited, but we tried to include as much genetic diversity as possible. Indeed, we detected important phenotypic differences in terms of susceptibility to MWMV. Our data revealed that $C$. ecuadorensis plants did not show symptoms after MWMV mechanical inoculation and had no or low MWMV accumulation compared with susceptible controls. C. ecuadorensis is reported to be resistant to a variety of viruses, including ZYMV, PRSV-W (the cucurbit infecting type), and WMV (Cutler and Whitaker 1968; Paran et al. 1989; Provvidenti and Gonsalves 1982). Resistance to ZYMV in this species seems to be controlled by more than one gene and was shown to be partially dominant (Paran et al. 1989); however, to our knowledge, no further characterization has been carried out for this resistance. Our genetic analysis indicated that resistance to MWMV in C. ecuadorensis accession PI 432441 is likely controlled by two recessive genes. All individuals of an $\mathrm{F} 1$ generation from a crossing with the squash breeding line A-0501-6 were fully susceptible, indicating that the resistance is recessive, and phenotypic segregation of an F2 generation fit well with the expected 1:15 ratio, suggesting the implication of two genes. Recessive potyvirus resistances have been associated with $e I F 4 E$ alleles in a significant number of cases (reviewed in Bastet et al. 2017; Hashimoto et al. 2016; Sanfaçon 2015; Truniger and Aranda 2009); indeed, melon plants silenced for eIF4E expression were fully resistant to MWMV (Rodríguez-Hernández et al. 2012). These data, together with the recent finding of the paleo-tetraploid nature of the Cucurbita genome (Montero-Pau et al. 2018; Sun et al. 2017), led us to hypothesize that the two genes controlling PI 432441 resistance to MWMV could be the two eIF4E paralogs probably present in the C. ecuadorensis genome. Using conserved primers, we cloned and sequenced CeeIF4E1 and CeeIF4E2; a comparison of their modeled three-dimensional structures with that of the recently described melon eIF4E crystal structure (Miras et al. 2017) indicated the existence of amino acid substitutions in regions of the protein where potyvirus resistance substitutions occur (Miras et al. 2017; Truniger and Aranda 2009). Thus, we developed specific markers for the CeeIF4E1, CeeIF4E2, CpeIF4E1, and CpeIF4E2 alleles involved in the crossing of PI $432441 \times$ A-0501-6 and performed an association analysis using F2 individuals. However, our results did not support an association of either allele with PI 432441 resistance, particularly considering the recessive nature of the resistance demonstrated by the phenotype of the F1 population. Nevertheless, we believe that the implication of eIF4E genes in the control of the susceptibility of PI 432441 plants to MWMV cannot be ruled out, as functional replacement by allelic forms seems to be frequent in eIF4E-controlled resistance, a phenomenon probably even more complex for polyploid genomes (Gauffier et al. 2016; Julio et al. 2015; Nellist et al. 2014). Moreover, since resistance to MWMV seems to be controlled by two recessive genes, the other gene involved could be $e I F$ (iso) $4 E$, as previous studies show that mutations in both $e I F 4 E$ and $e I F($ iso $) 4 E$ in pepper were required to confer resistance to pepper veinal mottle virus and chilli veinal mottle virus (Hwang et al. 2009; Ruffel et al. 2006). In conclusion, the generation of further segregating populations such as F3s and backcrosses to parents together with additional genetic studies are needed to identify good candidate genes for the PI 432441 resistance to MWMV. In any case, PI 432441 seems to be a good source for introgression of resistance to MWMV in C. pepo.

\section{ACKNOWLEDGMENTS}

We thank P. Mayor and C. M. Mengual for technical assistance, J. Abad for advice on the Cucurbita spp. accessions to screen, T. Jarman for providing seeds of the susceptible cultivar A-0501-6, and M. A. SánchezPina and V. Truniger for critically reading the manuscript.

\section{LITERATURE CITED}

Arocha, Y., Vigheri, N., Nkoy-Florent, B., Bakwanamaha, K., Bolomphety, B., Kasongo, M., Betts, P., Monger, W. A., Harju, V., Mumford, R. A., and Jones, P. 2008. First report of the identification of Moroccan watermelon mosaic virus in papaya in Democratic Republic of Congo. Plant Pathol. 57:387.

Bananej, K., Orfanidou, C. G., Maliogka, V. I., and Katis, N. I. 2018. First report of Moroccan watermelon mosaic virus in zucchini in Iran. Plant Dis. 102:2047.

Bastet, A., Robaglia, C., and Gallois, J.-L. 2017. eIF4E resistance: Natural variation should guide gene editing. Trends Plant Sci. 22:411-419.

Brown, R. N., Bolanos-Herrera, A., Myers, J. R., and Jahn, M. M. 2003. Inheritance of resistance to four cucurbit viruses in Cucurbita moschata. Euphytica 129:253-258.

Chandrasekaran, J., Brumin, M., Wolf, D., Leibman, D., Klap, C., Pearlsman, M., Sherman, A., Arazi, T., and Gal-On, A. 2016. Development of broad virus resistance in non-transgenic cucumber using CRISPR/Cas9 technology. Mol. Plant Pathol. 17:1140-1153.

Chatzivassiliou, E. K., Papapanagiotou, A. P., Mpenardis, P. D., Perdikis, D. C., and Menexes, G. 2016. Transmission of Moroccan watermelon mosaic virus (MWMV) by aphids in Greece. Plant Dis. 100:601-606. 
Cutler, H. C., and Whitaker, T. W. 1968. A new species of Cucurbita from Ecuador. Ann. Mo. Bot. Gard. 55:392-396.

Desbiez, C., Joannon, B., Wipf-Scheibel, C., Chandeysson, C., and Lecoq, H. 2009. Emergence of new strains of Watermelon mosaic virus in Southeastern France: Evidence for limited spread but rapid local population shift. Virus Res. 141:201-208.

Fischer, H. U., and Lockhart, B. E. L. 1974. Serious losses in cucurbits caused by watermelon mosaic virus in Morocco. Plant Dis. Rep. 58:143-146.

Food and Agriculture Organization (FAO). 2016. FAOSTAT. Food and Agriculture Organization of the United Nations. http://faostat.fao.org/site/342/ default.aspx

Gallois, J.-L., Moury, B., and German-Retana, S. 2018. Role of the genetic background in resistance to plant viruses. Int. J. Mol. Sci. 19:2856.

Gao, Z., Johansen, E., Eyers, S., Thomas, C. L., Noel Ellis, T. H., and Maule, A. J. 2004. The potyvirus recessive resistance gene, sbm1, identifies a novel role for translation initiation factor eIF4E in cell-to-cell trafficking. Plant J. 40:376-385

Gauffier, C., Lebaron, C., Moretti, A., Constant, C., Moquet, F., Bonnet, G., Caranta, C., and Gallois, J.-L. 2016. A TILLING approach to generate broad-spectrum resistance to potyviruses in tomato is hampered by eIF4E gene redundancy. Plant J. 85:717-729.

Grumet, R., Kabelka, E., McQueen, S., Wai, T., and Humphrey, R. 2000. Characterization of sources of resistance to the watermelon strain of Papaya ringspot virus in cucumber: Allelism and co-segregation with other potyvirus resistances. Theor. Appl. Genet. 101:463-472.

Hashimoto, M., Neriya, Y., Yamaji, Y., and Namba, S. 2016. Recessive resistance to plant viruses: Potential resistance genes beyond translation initiation factors. Front. Microbiol. 7:1695.

Hwang, J., Li, J., Liu, W.-Y., An, S.-J., Cho, H., Her, N. H., Yeam, I., Kim, D., and Kang, B.-C. 2009. Double mutations in eIF4E and eIFiso4E confer recessive resistance to Chilli veinal mottle virus in pepper. Mol. Cells 27: 329-336.

Ibaba, J. D., Laing, M. D., and Gubba, A. 2016. Genome sequence analysis of two South African isolates of Moroccan watermelon mosaic virus infecting cucurbits. Virus Genes 52:896-899.

Juárez, M., Kassem, M., Sempere, R., Gómez, P., Mengual, C., and Aranda, M. A. 2013a. Hortícolas. Virus de cucurbitáceas en el sureste español: Viejos conocidos y nuevas amenazas. Phytoma España 251:31.

Juárez, M., Legua, P., Mengual, C., Kassem, M., Sempere, R., Gómez, P., Truniger, V., and Aranda, M. A. 2013b. Relative incidence, spatial distribution and genetic diversity of cucurbit viruses in eastern Spain. Ann. Appl. Biol. 162:362-370.

Julio, E., Cotucheau, J., Decorps, C., Volpatti, R., Sentenac, C., Candresse, T., and De Borne, F. D. 2015. A eukaryotic translation initiation factor 4E (eIF4E) is responsible for the "va" tobacco recessive resistance to potyviruses. Plant Mol. Biol. Report. 33:609-623.

Kabelka, E., and Grumet, R. 1997. Inheritance of resistance to the Moroccan watermelon mosaic virus in the cucumber line TMG-1 and cosegregation with zucchini yellow mosaic virus resistance. Euphytica 95:237-242.

Lecoq, H. 2003. Cucurbits. Pages 665-688 in: Virus and Virus-like Diseases of Major Crops in Developing Countries. LoebensteinG., and Thottappilly, G., eds. Springer, Dordrecht, The Netherlands.

Lecoq, H., Dafalla, G., Desbiez, C., Wipf-Scheibel, C., Delécolle, B., Lanina, T., Ullah, Z., and Grumet, R. 2001. Biological and molecular characterization of Moroccan watermelon mosaic virus and a potyvirus isolate from Eastern Sudan. Plant Dis. 85:547-552.

Lecoq, H., and Desbiez, C. 2012. Viruses of cucurbit crops in the Mediterranean Region. Adv. Virus Res. 84:67-126.

Lecoq, H., Justafré, I., Wipf-Scheibel, C., and Desbiez, C. 2008. Moroccan watermelon mosaic virus newly reported on zucchini squash in France. Plant Pathol. 57:766.

Ling, K. S., Harris, K. R., Meyer, J. D. F., Levi, A., Guner, N., Wehner, T. C., Bendahmane, A., and Havey, M. J. 2009. Non-synonymous single nucleotide polymorphisms in the watermelon eIF4E gene are closely associated with resistance to Zucchini yellow mosaic virus. Theor. Appl. Genet. 120:191-200.

Lole, K. S., Bollinger, R. C., Paranjape, R. S., Gadkari, D., Kulkarni, S. S., Novak, N. G., Ingersoll, R., Sheppard, H. W., and Ray, S. C. 1999. Full-length human immunodeficiency virus type 1 genomes from subtype $\mathrm{C}$-infected seroconverters in India, with evidence of intersubtype recombination. J. Virol. 73:152-160.

Malandraki, I., Vassilakos, N., Xanthis, C., Kontosfiris, G., Katis, N. I., and Varveri, C. 2013. First report of Moroccan watermelon mosaic virus in zucchini crops in Greece. Plant Dis. 98:702.

Meer, F. W., and Garnett, H. M. 1987. Purification and identification of a South African isolate of watermelon mosaic virus-Morocco. J. Phytopathol. 120:255-270.
Menzel, W., Abang, M. M., and Winter, S. 2011. Characterization of cucumber vein-clearing virus, a whitefly (Bemisia tabaci G.)-transmitted carlavirus. Arch. Virol. 156:2309-2311.

Miras, M., Truniger, V., Silva, C., Verdaguer, N., Aranda, M. A., and Querol, J. 2017. Structure of eIF4E in complex with an eIF4G peptide supports a universal bipartite binding mode for protein translation. Plant Physiol. 174: 1476-1491.

Montero-Pau, J., Blanca, J., Bombarely, A., Ziarsolo, P., Esteras, C., Martí-Gómez, C., Ferriol, M., Gómez, P., Jamilena, M., Mueller, L., Picó, B., and Cañizares, J. 2018. De novo assembly of the zucchini genome reveals a whole-genome duplication associated with the origin of the Cucurbita genus. Plant Biotechnol. J. 16:1161-1171.

Nellist, C. F., Qian, W., Jenner, C. E., Moore, J. D., Zhang, S., Wang, X., Briggs, W. H., Barker, G. C., Sun, R., and Walsh, J. A. 2014. Multiple copies of eukaryotic translation initiation factors in Brassica rapa facilitate redundancy, enabling diversification through variation in splicing and broad-spectrum virus resistance. Plant J. 77:261-268.

Nicaise, V., German-Retana, S., Sanjuán, R., Dubrana, M.-P., Mazier, M., Maisonneuve, B., Candresse, T., Caranta, C., and LeGall, O. 2003. The eukaryotic translation initiation factor $4 \mathrm{E}$ controls lettuce susceptibility to the potyvirus Lettuce mosaic virus. Plant Physiol. 132:1272-1282.

Nieto, C., Morales, M., Orjeda, G., Clepet, C., Monfort, A., Sturbois, B., Puigdomènech, P., Pitrat, M., Caboche, M., Dogimont, C., Garcia-Mas, J., Aranda, M. A., and Bendahmane, A. 2006. An eIF4E allele confers resistance to an uncapped and non-polyadenylated RNA virus in melon. Plant J. 48:452-462.

Paran, I., Shifriss, C., and Raccah, B. 1989. Inheritance of resistance to Zucchini yellow mosaic virus in the interspecific cross Cucurbita maxima $\times$ C. ecuadorensis. Euphytica 42:227-232.

Provvidenti, R. 1991. Inheritance of resistance to the Florida strain of zucchini yellow mosaic virus in watermelon. HortScience 26:407-408.

Provvidenti, R., and Gonsalves, D. 1982. Resistance to Papaya ringspot virus in Cucumis metuliferus and its relationship to resistance to Watermelon mosaic virus 1. J. Hered. 73:239-240.

Rodríguez-Hernández, A. M., Gosalvez, B., Sempere, R. N., Burgos, L., Aranda, M. A., and Truniger, V. 2012. Melon RNA interference (RNAi) lines silenced for Cm-eIF4E show broad virus resistance. Mol. Plant Pathol. 13:755-763.

Roggero, P., Dellavalle, G., Lisa, V., and Stravato, V. M. 1998. First report of Moroccan watermelon mosaic potyvirus in zucchini in Italy. Plant Dis. 82:351.

Roy, A., Kucukural, A., and Zhang, Y. 2010. I-TASSER: A unified platform for automated protein structure and function prediction. Nat. Protoc. 5: 725-738.

Ruffel, S., Dussault, M. H., Palloix, A., Moury, B., Bendahmane, A., Robaglia, C., and Caranta, C. 2002. A natural recessive resistance gene against potato virus $\mathrm{Y}$ in pepper corresponds to the eukaryotic initiation factor 4E (eIF4E). Plant J. 32:1067-1075.

Ruffel, S., Gallois, J. L., Lesage, M. L., and Caranta, C. 2005. The recessive potyvirus resistance gene pot-1 is the tomato orthologue of the pepper pvr2eIF4E gene. Mol. Genet. Genomics 274:346-353.

Ruffel, S., Gallois, J.-L., Moury, B., Robaglia, C., Palloix, A., and Caranta, C. 2006. Simultaneous mutations in translation initiation factors eIF4E and eIF (iso) $4 \mathrm{E}$ are required to prevent pepper veinal mottle virus infection of pepper. J. Gen. Virol. 87:2089-2098.

Sanfaçon, H. 2015. Plant translation factors and virus resistance. Viruses 7: 3392-3419.

Sun, H., Wu, S., Zhang, G., Jiao, C., Guo, S., Ren, Y., Zhang, J., Zhang, H., Gong, G., and Jia, Z. 2017. Karyotype stability and unbiased fractionation in the paleo-allotetraploid Cucurbita genomes. Mol. Plant 10:1293-1306.

Truniger, V., and Aranda, M. A. 2009. Recessive resistance to plant viruses. Adv. Virus Res. 75:119-159.

Ullah, Z., and Grumet, R. 2002. Localization of Zucchini yellow mosaic virus to the veinal regions and role of viral coat protein in veinal chlorosis conditioned by the zym potyvirus resistance locus in cucumber. Physiol. Mol. Plant Pathol. 60:79-89.

Wai, T., and Grumet, R. 1995. Inheritance of resistance to the watermelon strain of papaya ringspot virus in the cucumber line TMG-1. HortScience 30:338-340

Wangkumhang, P., Chaichoompu, K., Ngamphiw, C., Ruangrit, U., Chanprasert, J., Assawamakin, A., and Tongsima, S. 2007. WASP: A web-based allelespecific PCR assay designing tool for detecting SNPs and mutations. BMC Genomics 8:275.

Yakoubi, S., Desbiez, C., Fakhfakh, H., Wipf-Scheibel, C., Marrakchi, M., and Lecoq, H. 2008. Biological characterization and complete nucleotide sequence of a Tunisian isolate of Moroccan watermelon mosaic virus. Arch. Virol. 153:117-125. 